American Journal of Agricultural and Biological Sciences 6 (1): 92-98, 2011

ISSN 1557-4989

(C) 2010 Science Publications

\title{
Evaluation of a Candelilla Wax-Based Edible Coating to Prolong the Shelf-Life Quality and Safety of Apples
}

\author{
${ }^{1}$ Emilio Ochoa, ${ }^{1}$ Saúl Saucedo-Pompa, ${ }^{1}$ Romeo Rojas-Molina, ${ }^{1}$ Heliodoro de la Garza, \\ ${ }^{2}$ Ana Verónica Charles-Rodríguez and ${ }^{1}$ Cristóbal Noé Aguilar \\ ${ }^{1}$ Department of Food Science and Technology, School of Chemistry, \\ Universidad Autónoma de Coahuila, Saltillo, 25280, Coahuila, México \\ ${ }^{2}$ Department of Animal Science, Universidad Autónoma Agraria “Antonio Narro", \\ Col. Buenanivsta, Saltillo, 25315, Coahuila, México
}

\begin{abstract}
Problem statement: The apple by its nature as perishable food of climacteric type implies that even under refrigerated conditions, the fruit spoils quickly by its very nature of breathing and similarly are attacked by microorganisms of different types that make is the fruit spoil even faster so in the present investigation be worked with an edible coating to protect it from decomposition and contamination by phytopathogens microorganisms. Approach: This study reports the effect of the application of an edible coating elaborated with a natural wax extracted from Euphorbia antisyphilitica and containing $0.01 \%$ of a potent antioxidant, Ellagic Acid (EA), on the shelf life quality and safety of "Golden Delicious" apples. This new film extended and improved the quality of fresh apples. In a first experimental step, the edible coating was applied on apples and the characteristics evaluated were changes in the appearance, weight loss, total solids content and a sensorial evaluation was included. In a second experimental step, the capacity of protection of the edible coating was evaluated against three important phytopathogenic fungi (Colletrotrichum gloesporioides, Fusarium oxysporum and Penicillum expansum). Results: demonstrated that EA-based edible coating prevents apparent damages to the fruits. In general, the film showed better results in comparison with the control (apples without coating). The EA-based coating diminished in greater proportion the change of color, weight loss, total solids content and it was not perceived by the sensorial panel. Results of second experimental step, demonstrated the edible EA-based coating is an excellent antifungal barrier against all microorganisms tested. Conclusion: The application of this new edible film for apples extends their shelf life and elevates the antioxidant potential, as well as their nutritional quality.
\end{abstract}

Key words: Ellagic Acid (EA), candelilla wax, Penicillum expansum, F. oxyporum, phytopathogenic fungi, Euphorbia antisyphilitica, wax-based edible

\section{INTRODUCTION}

Consumers demand less use of chemicals on minimally processed fruits and vegetables so more attention has been paid to the search for naturally occurring substances able to act as alternative antimicrobials and antioxidants (Ponce et al., 2008). The antimicrobial coating is a rapidly developing technology that can be employed for controlling the microbiological decay of perishable food products (Nobile et al., 2008). Different organic and inorganic active agents can be incorporated into the polymeric structure to prevent the undesirable microbial spoilage occurring during storage of packaged fresh food (Appendini and Hotchkiss, 2002). The use of edible films and coatings in food protection and preservation has recently increased since they offer several advantages over synthetic materials, such as being biodegradable and ecofriendly (Tharanathan, 2003; Puoci et al., 2008).

These films could prolong the shelf life and safety of foods by preventing growth of pathogenic and spoilage microorganisms as a result of their lag-phase extension and/or their growth rate reduction (Quintavalla and Vicini, 2002). The ability of edible films to retard moisture, oxygen, aromas and solute transport may be improved by including additives such as antioxidants, antimicrobials, colorants,

Corresponding Author: Emilio Ochoa, Department of Food Science and Technology, School of Chemistry, Universidad Autónoma de Coahuila, Saltillo, 25280, Coahuila, México

Tel: +52 8444161238 Fax: +52 8444159534 
flavours, fortifying nutrients and spices in film formulation (Pranoto et al., 2005).

For the present study a system integrated by two active compounds was evaluated: Ellagic acidcandelilla wax. The main component of the edible coating is the candelilla wax, a material derived from candelilla plant (Euphorbia antisyphilitica Zucc.), which grows normally in desert environment, principally in calcium rich soils and it is originally from arid zones from Mexico and South-Western United States.

Ellagic acid (2,3,7,8-Tetrahydroxy-chromeno [5,4,3-cde]chromene-5,10-dione) is the main monomer of ellagitannins, which are secondary metabolites presents in the some superior plants. Several medicinal and industrial applications have been found for this acid such as, antitumoral, antioxidant, antimicrobial, antiviral, antiflamatory activities; in addition reduce the heart diseases (Aguilera-Carbó et al., 2008).

The objective of this study was to evaluate the effect of the application of an edible coating elaborated with a natural wax extracted from Euphorbia antisyphilitica and containing $0.01 \%$ of a potent antioxidant, Ellagic Acid (EA), on the shelf life quality of "Golden Delicious" applesand their capacity as antifungal barrier due some phytopathogenic fungi.

\section{MATERIALS AND METHODS}

In a first experimental step, physicochemical and sensorial changes were evaluated, while in a second step, the efficiency as antifungal barrier of the candelilla wax coating with ellagic acid was determined. Beneficial effects of fruit coatings include improvement of appearance and reduction of weight loss.

Raw material: A lot of 400 fruits of Golden Delicious apple with a similar physiological maturity and free of apparent damages were obtained in Arteaga City, Coahuila, Mexico. Apples were washed and disinfected (500 ppm sodium hypochlorite). Prior to their use in the experiment, the fruits were harvested $24 \mathrm{~h}$ before to the coating was applied. Ellagic acid was acquired from ICN reagents, Monterrey, Nuevo Leon, Mexico. All the materials used in this study were food-grade.

Candelilla wax extraction: The wax was extracted from the candelilla plant. The plant was collected in southeastern of Coahuila state, Mexico. Candelilla stems were cut and submitted by immersion in a solution of citrates $1 \%$ and $80^{\circ} \mathrm{C}$ in a stainless steel container (patent requested), on the surface of the container float a bowl which was collected, this product is called cerote, which is subjected to a refining process (Saucedo-Pompa et al., 2009), the product obtained was characterized by infrared spectroscopy FTspectrophotometer IR Spectrum GX Perkin-Elmer, to characterized the wax obtained.

Formulation and application of edible coating: For coating formulation (patent requested) polymer resin used was kindly provided by DIA (UAdeC), a jojoba oils was used as plasticizer and ellagic acids as antioxidant. The components of edible coating were mixed in water following the reported by SaucedoPompa (2007). Mixture was heated at $80^{\circ} \mathrm{C}$ and homogenized at $2500 \mathrm{rpm}$ in an industrial homogenizer (International $^{\mathrm{TM}}$ Mod. LI-17V). Fruits were carefully submerged in the dispersion by a period of $2 \mathrm{~s}$ and then were put under an air flux until the solidification of edible coating. This process was repeated one more time. After, the apples were stored at room temperature in perforated polystyrene trays. Apples treated with candelilla wax and ellagic acid was coded as ECEA. Two control treatments were included in the experiment, apples with Edible Coating of candelilla wax without Ellagic Acid (EC) and Without Cover apples (WC).

Evaluation of shelf life quality: Weight loss of apples during the storage period ( 8 weeks) was measured with a semi-analytical balance (Explorer, OHAUS). Appearance changes were evaluated with the use of a photographic camera (13.6 Mpix Ciber Shot, Sony). Total solids content was evaluated in a refractometer (PCE-Oe). Each sample was analyzed with six replicates.

Sensory evaluation: Sensorial differences among treatments were evaluated using a triangular test (Larmond, 1977; Ruiz-Cruz et al., 2010). In a first assay, differences in appearance were evaluated using wholes apples. In a second assay, flavor of apples was evaluated using small pieces of cut apples. Panel of evaluation was integrated by 50 judges. Triplicates of each assay were analyzed.

Experimental step; fungal strains: Spores of three fungal strains (Colletrotrichum gloesporioides, Fusarium oxysporum and Penicillum expansum from the 
DIA-UAdeC collection) conserved in a criosystem at -70 ${ }^{\circ} \mathrm{C}$ were inoculated on Potato Dextrose Agar (PDA). Petri dishes of PDA were incubated at $30^{\circ} \mathrm{C}$ during 5 days and the produced spores were harvested with a sterile solution of $0.01 \%$ Tween 80 and counted in a Neubauer chamber.

Microbiological assay: Harvested spores from the three fungal cultures (PDA plates) were inoculated in covered and uncovered apples. An inoculation level of $2 \times 10^{7}$ spores per each fruit was used. All fruits were put in polystyrene trays adapted with a special orifice with cotton cork, which permitted the respiration process and avoided the humidity accumulation. Trays were incubated at $22.2-22.4^{\circ} \mathrm{C}$ and $62-63 \%$ of relative humidity, during a period of 5 weeks. Changes in appearance were evaluated with the following scale: $0=$ without damage, $1=$ slight damage $(<25 \%), 2=$ moderate damage $(>25 \%$ and $<50 \%), 3=$ severe damage $(>50 \%$ and $<75 \%)$ and $4=$ rotten fruit $(75 \%-100 \%)$. IDC $=\Sigma$ (damage level) * (Number of fruits per level) / Total number of fruits.

Included treatments were: SC-A (fruits without coating and inoculated with $F$. oxysporum); SC-B (fruits without coating and inoculated with C. gloesporioides); SC-C (fruits without coating and inoculated with $P$. expansum); CC-A (fruits with coating without ellagic acid and inoculated with F. oxyporum); CC-B (fruits with coating without ellagic acid and inoculated with $C$. gloesporioides); CC-C (fruits with coating without ellagic acid and inoculated with $P$. expansum); CCA-A (fruits with coating with ellagic acid and inoculated with F. oxyporum); CC-B (fruits with coating with ellagic acid and inoculated with $C$. gloesporioides); CC-C (fruits with coating with ellagic acid and inoculated with P. expansum). Control treatments were: SC-SI (fruits without coating non inoculated); CC-SI (fruits with coating non inoculated) and CCA-SI (fruits with coating with ellagic acid but non inoculated).

Experimental design and data analysis: For the first experimental step, a randomized experimental design with factorial fix $3 * 8$ with six replicates was used. Three were the number of levels of factor 1 (kind of coating) and 8 was the number of levels factor 2 (storage time). For the microbiological assay, 3 treatments with 4 groups and 3 replicates were employed. Obtained data were statistically analyzed with an analysis of variance using the Minitab ${ }^{\circledR}$ 15.1.30.0 software. Mean of values were compared through a t-student test $(\alpha=0.05)$. For results of sensorial evaluation, data were analysed using an E.B. Roessler table.

\section{RESULTS}

Candelilla wax characterization by FT-IR: The major chemical components of the candelilla wax are esters of long chain fatty acids (Saucedo-Pompa et al., 2009), which it was found with a FT-IR spectrum of wax extracted from control (Fig. 1). As it can be seen in the FT-IR spectrum (ATR) of candelilla wax sample, the presence of $\mathrm{C}-\mathrm{H}$ stretching bands, characteristic of saturarted carbon, appeared in a range from 2953-2849 $\mathrm{cm}$; followed by the presence of small signals in a narrow range from $2178-1995 \mathrm{~cm}^{-1}$, corresponding to the presence of different $\mathrm{C}-\mathrm{H}$ stretching.

In the area of $1737 \mathrm{~cm}^{-1}$ is a band corresponding to stretching $\mathrm{C}=\mathrm{O}$, indicating the presence of carbonyl functions present in the wax, followed by the presence of the bands at $1462 \mathrm{~cm}^{-1}$ and $1377 \mathrm{~cm}^{-1}$, corresponding to interactions $\mathrm{O}-\mathrm{C}-\mathrm{H}$, which presents a characteristic band of candelilla wax for the presence of these functional groups.

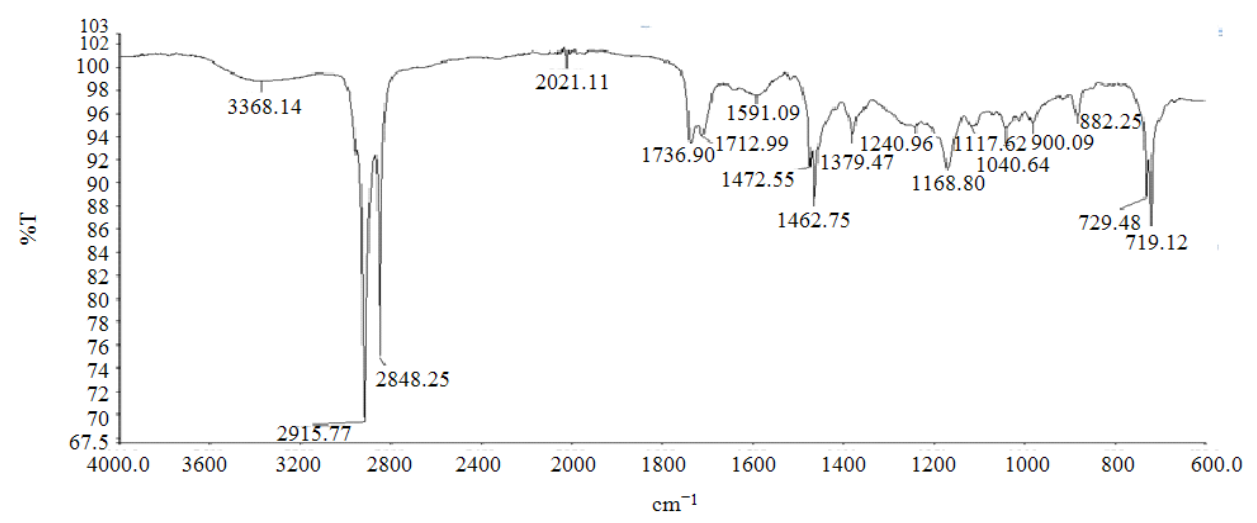

Fig. 1: FT-IR spectrum of candelilla wax extracted 


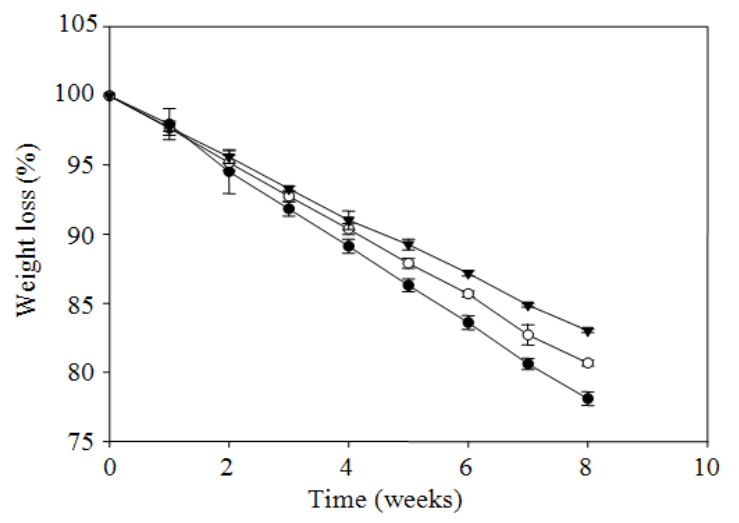

Fig. 2: Weight loss in fruits (apples) after of 8 weeks of storage at room temperature. $\boldsymbol{\nabla}$ apples with coating and ellagic acid (CCA); o apples with coating (CC) and $\bullet$ apples without coating (SC)

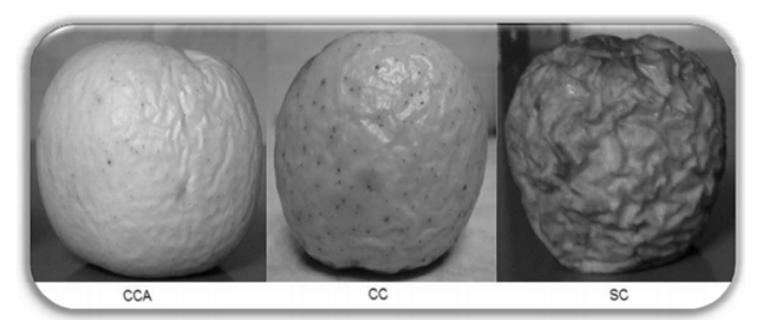

Fig. 3: Changes of appearance on apples at 8 weeks of storage at room temperature. CCA-apples with coating and ellagic acid, CC-apples with coating, SC- apples without coating

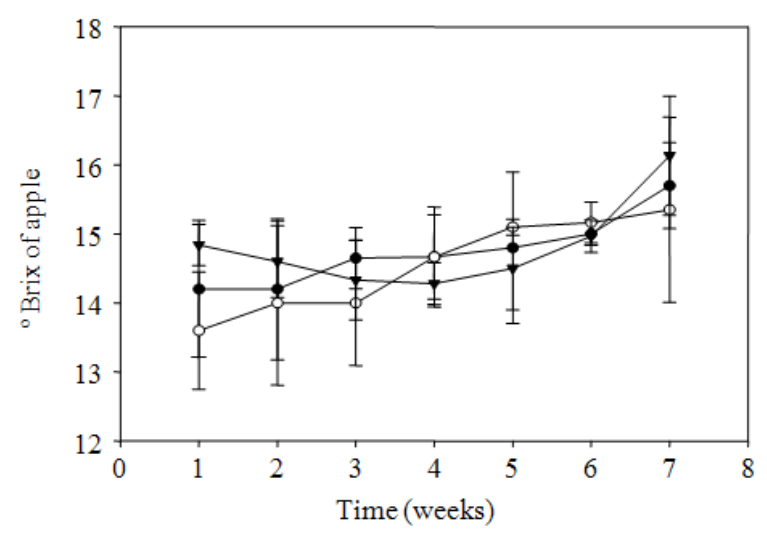

Fig. 4: Changes in soluble solid content or ${ }^{\circ}$ Brix (SSC) after of 7 weeks of storage of the apples at room temperature. $\boldsymbol{\nabla}$ apples with coating and ellagic acid (CCA); $\bigcirc$ apples with coating (CC) and $\bullet$ apples without coating (SC)

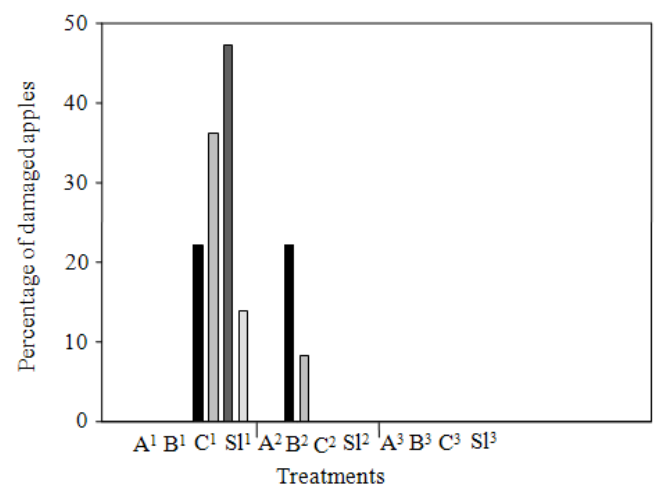

Fig. 5: Fungal Damages. A-apples inoculated with F. oxysporum; B-apples inoculated with $C$. gloeosporioides; C-apples inoculated with $P$. expansum and SI-apples non inoculated. 1without coating (SC); 2-with coating (CC) and 3 -with coating and ellagic acid (CCA)

Weight loss: During the storage period, the edible coating was effective in slowing down weight loss. In all treatments, the weight loss was increased $(p<0.05)$ during the period of study. The fruits whit ECEA showed the lowest weight loss (Fig. 2). The use of ellagic acid as part of edible films diminished the moisture loss in fruits.

Appearance changes in apples: Appearance changes in fruits were evident at end of the storage period (8 weeks). Figure 3 shows that apples with candelilla wax and ellagic acid presented the minor level of changes, while apples without coating were seriously aged.

Solid contents: No changes in the total solid contents in all treatments were evidenced during the storage period. Figure 4 shows a slight increment but no significant in the total solid content of apples with CCA treatment.

Sensorial evaluation: Results of sensorial evaluation demonstrated that with the number of correct answers by the judges and comparing them with the corresponding table, there were not significant differences among all treatments (significance level of $1 \%$ ) in both assays, for appearance and flavor. It means that edible coatings did not modify the colors and flavors of apples.

Antifungal test: When edible coatings were applied to apples for evaluation of their efficiency as antifungal barrier, it was possible to demonstrate that the use of edible coating of candelilla wax with ellagic acid inhibited completely the fungal growth of the three fungi tested (Fig. 5). Application of candelilla wax 
without ellagic acid permitted the growth of $C$. gloesporioides and $P$. expansum and inhibited the growth of $F$. oxysporum. Apples without an edible coating were totally invaded by the growth of the three fungal strains.

\section{DISCUSSION}

These data of FT-IR are similar to those obtained by Saucedo-Pompa et al. (2009), who reported the characterization of candelilla wax obtained by different techniques, in all the waxes obtained found the same similarities in functional groups and establish this technique to characterize and identify candelilla wax.

For fruits the reduction in weight loss is very important and the use of edible films is an excellent tool to control the reduction in. These results are similar to those found by Hoa et al. (2008) who reported that the use of lipid-based reduced weight loss in 'cat Hoa loc' mangoes after 1 week at room temperature, just as Assis and Pessoa (2007) reported that these coatings applied to apples reduce the loss of moisture. This is due to the barrier formed around the fruit, which prevents the loss of water vapor (Ghaouth et al., 1991; Islas-Osuna et al., 2010). According to Hagenmaier and Baker (1993), the use of cereous materials as fruit coatings diminishes the concentration of oxygen and increase the carbon dioxide in the fruit, that reduce the number of pores by which the water steam and other gases are exchanged (ISTH, 1990).

The use of edible coatings considerably reduce apparent changes in apples this was demonstrated by Perez-Gago et al. (2005). These changes can be due to modification of internal atmosphere of the fruit, with high levels of carbon dioxide and low levels of oxygen, retarding the maturity process (Bosquez-Molina et al., 2003; Gonzales-Aguilar et al., 2005).

The applications of edible films made with edible wax did not affect the quality parameters of fruits, presenting a normal behavior in the maturity of those with increment in the $\mathrm{pH}$ values and the solid content (Bringas-Taddei et al., 2005). However, obtained results are according with those reported by Galietta et al. (2005) and Baldwin et al. (1999), who indicated there was not effect of coating on the Brix grades, remaining stable during the storage period of fruits.

Sensorial evaluation it is very important, because at the moment of evaluation of consumer preferences, they don't have the same concepts of taste, provoking an ample margin of preferences. It means that each consumer can to have a particular idea of flavor or appearance with respect to the product evaluated (Bárcenas et al., 2001). Sensorial evaluation of this study clearly demonstrated that the consumer was not able to detect visual or taste differences among treated and untreated fruits. By this reason, the application of candelilla wax with ellagic acid is an excellent alternative to preserve Golden Delicious apples, even and when Witting et al. (2005) mentioned that the organoleptic preferences for many foods are strongly influenced by the regional culture.

The fungal growth in apples is due to moisture loss, release of ions and other cell components, which provide a rich medium for the development of the microorganisms (Brackett, 1987) and precisely this is avoided by the application of edible coating. For this reason it is possible to prolong the shelf life quality providing an important antifungal activity. Rojas-Graü et al. (2006) reported that application of edible films retard the microbiological damage of applesand it is possible to improve this property if phenolic additives are added to the formulation (Farag et al., 1989). Reported the inhibition of Penicillium spp. in carrots when a film of quitosan and citric acid was used. The results obtained are similar to found by Maftoonazad et al. (2007), they evaluated the effect of an edible coating in avocado exposed to Lasiodiplodia theobromae infection, they reported that Progress of disease in avocado fruit induced by L. theobromae, was affected by use of edible coating.

\section{CONCLUSION}

Edible coating of candelilla wax with ellagic acid prolongs and improves the shelf life quality of Golden Delicious apples during 8 weeks of storage without altering the sensorial quality of the fruits. This edible coating demonstrated to be an excellent antifungal barrier inhibiting the growth of natural phytophatogenic fungal strains. The parameters evaluated showed that the use of ellagic acid, representing an attractive alternative to protect fruit. Even the use of cover quality control improves shelf life of apples.

\section{ACKNOWLEDGEMENT}

The researchers are grateful to the Mexican Program of CONACYT-CONAFOR (Project No. 2008C01) for the financial support of this study. Authors Saúl Saucedo-Pompa and Romeo Rojas-Molina want to thank to Mexican Council of Science and Technology (CONACYT) by their scholarships received for their postgraduate studies.

\section{REFERENCES}

Aguilera-Carbó, A., C. Augur, L.A. Prado-Barragan, E. Favela-Torres and C. N. Aguilar, 2008. Microbial production of ellagic acid and biodegradation of ellagitannins. Microbiol. Biotechnol., 78: 189-199, DOI: $10.1007 / \mathrm{s} 00253-007-1276-2$ 
Appendini, P. and J.H. Hotchkiss, 2002. Review of antimicrobial food packaging. Innovative Food Sci. Emerg. $\quad$ Technol., 3: 113-126. DOI: 10.1016/S1466-8564(02)00012-7

Assis, O. and J. Pessoa, 2007. Scientific note: Preparation of thin films of chitosan for use as edible coatings to inhibit fungal growth on sliced fruits. Brazilian j. Food Sci., 7: 17-22. ISSN: 1517-7645

ISTH, 1990. Proceedings of the Interamerican Society of Tropical Horticulture. 1st Edn., Print Shoppe, USA., pp: 300.

Baldwin, E.A., J.K. Burns, W. Kazokas, J.K. Brecht and R.D. Hagenmaier et al., 1999. Effect of two edible coatings with different permeability characteristics on mango (Mangifera indica L.) ripening during storage. Postharvest Biol. Technol., 17: 215-226. DOI: 10.1016/S09255214(99)00053-8

Bárcenas, P., R. Pérez de San Román, F.J. Pérez-Elortondo and M. Albisu, 2001. Consumer preference structures for traditional Spanish cheeses and their relationship with sensory properties. Food Qual. Preference, 12: 269-279. DOI: 10.1016/S09503293(01)00023-4

Bosquez-Molina, E., I. Guerrero-Legarreta and E. J. VernonCarter, 2003. Moisture barrier properties and morphology of mesquite gum-candelilla wax based edible emulsion coatings. Food Res. Int., 36: 885-893. DOI: 10.1016/S0963-9969(03)00097-8

Brackett, R.E., 1987. Microbiological consequences of minimally processed fruits and vegetables. J. Food Qual., 10: 195-206. DOI: $10.1111 /$ j.17454557.1987.tb00858.x

Nobile, Del, M.A., A. Conte, A.L. Incoronato and O. Panza, 2008. Antimicrobial efficacy and release kinetics of thymol from zein films. J. Food Engineer., 89: 57-63. DOI: 10.1016/j.jfoodeng.2008.04.004

Farag, R.S., Z.Y. Dw and S.H. Abo-raya, 1989. Influence of Some Spice Essential Oils on Aspergillus parasiticus Growth and Production of Aflatoxins in a synthetic medium. J. Food Sci., 54: 74-79. DOI: 10.1111/j.1365-2621.1989.tb08571.x

Galietta, G., F. Harte, D. Molinari, R. Capdevielle and W. Diano, 2005. Increased postharvest life of tomato using a film of whey protein. Latin Am. J. Technol. Postharvest, 6: 117-123. http://foodscience.tennessee.edu/FacultyMembers/ Harte.html

Ghaouth, E.L., J. Arul, R. Ponnampalam and M. Boulet, 1991. Chitosan coating effect on storability and quality of fresh strawberries. J. Food Sci., 56: 1618-1620. DOI: $10.1111 / \mathrm{j} .1365-$ 2621.1991.tb08655.x
Hagenmaier, R.D. and R.A. Baker, 1993. Reduction in gas exchange of citrus fruit by wax coatings. J. Agric. Food Chem., 41: 283-287. DOI: 10.1021/jf00026a029

Hoa, T.T. and D. Marie-Noëlle, 2008. Effects of different coatings on biochemical changes of 'cat Hoa loc' mangoes in storage. Postharvest Biol. Technol., 48: 150-152. DOI: 10.1016/j.postharvbio.2007.09.021

Islas-Osuna, M.A., N.A. Stephens-Camacho, C.A. ContrerasVergara, M. Rivera-Dominguez, E. Sanchez-Sanchez, M.A. Villegas-Ochoa and G.A. Gonzalez-Aguilar. 2010. Novel Postharvest Treatment Reduces Ascorbic Acid Losses in Mango (Mangifera indica L.) Var. Kent. Am. J. Agri. Bio. Sci., 3: 342-349. DOI: 10.3844/ajabssp.2010.342.349

Larmond, E., 1977. Laboratory methods for sensory evaluation of foods. 1st Edn., Agriculture Canada, Canada, ISBN-10: 0662012712, pp: 73.

Maftoonazad, N., H.S. Ramaswamy, M. Moalemiyan and A.C. Kushalappa, 2007. Effect of pectin-based edible emulsion coating on changes in quality of avocado exposed to Lasiodiplodia theobromae infection. Carbohydrate Polymers, 68: 341-349. DOI: 10.1016/j.carbpol.2006.11.020

Perez-Gago, M.B., M. Serra, M. Alonso, M. Mateos and M.A. del Río, 2005. Effect of whey proteinand hydroxypropyl methylcellulose-based edible composite coatings on color change of fresh-cut apples. Postharvest Biol. Technol., 36: 77-85. DOI: 10.1016/j.postharvbio.2004.10.009

Bringas-Taddei, E., J. Mercado-Ruiz, J. Garcia-Robles, González-Aguilar and G. Troncoso et al., 2005. Effect of calcium and edible wax treatments on overall quality of 'kent' mangoes during cold storage. Acta Hort. (ISHS), 682: 1281-1286. http://www.actahort.org/books/682/682_171.htm

Ponce, A.G., S.I. Roura, C.E. Del Vallea and M.R. Moreira, 2008. Antimicrobial and antioxidant activities of edible coatings enriched with natural plant extracts: In vitro and in vivo studies. Postharvest Biol. Technol., 49: 294-300. DOI: 10.1016/j.postharvbio.2008.02.013

Pranoto, Y. S.K., Rakshit and V.M. Salokhe, 2005. Enhancing antimicrobial activity of chitosan films by incorporating garlic oil, potassium sorbate and nisin. LWT-Food Sci. Technol., 38: 859-865. DOI: 10.1016/j.lwt.2004.09.014

Puoci, F., F. Iemma, U.G. Spizzirri, G. Cirillo, M. Curcio and N. Picci. 2008. Polymer in agriculture: A review. Am. J. Agri. Biol. Sci., 3: 299-314. DOI: 10.3844/ajabssp.2008.299.314 
Quintavalla, S. and L. Vicini, 2002. Antimicrobial food packaging in meat industry. Meat Sci., 62: 373-380. DOI: 10.1016/S0309-1740(02)00121-3

Tharanathan, R.N., 2003. Biodegradable films and composite coatings: Past, present and future. Trends Food Sci. Technol., 14: 71-78. DOI: 10.1016/S0924-2244(02)00280-7

Rojas-Graü, M.A., R.J. Avena-Bustillos, M. Friedman, P.R. Henika and O. Martín-Belloso et al., 2006. Mechanical, Barrier and AntimicrobiaL Properties of Apple Puree Edible Films Containing Plant Essential Oils. J. Agric. Food Chem., 54: 9262-9267. DOI: $10.1021 / \mathrm{jf061717u}$
Ruiz-Cruz, S., E. Alvarez-Parrilla, L.A. de la Rosa, A.I. Martinez-Gonzalez and J.J. Ornelas-Paz et al., 2010. Effect of different sanitizers on microbial, sensory and nutritional quality of fresh-cut jalapeno peppers. Am. J. Agri. Bio. Sci., 5: 331-341. DOI: 10.3844/ajabssp.2010.331.341

Saucedo-Pompa, S., R. Rojas-Molina, A.F. Aguilera-Carbó, A. Saenz-Galindo and H. De la Garza, 2009. Edible film based on candelilla wax to improve the shelf life and quality of avocado. Food Res. Int., 42: 511-515. DOI: 10.1016/j.foodres.2009.02.017 